\title{
PRESSURE TESTING OF MICRO BALLOONS BY BURSTING
}

\author{
Mike A. Salazar, Pete Gobby, Robert Watt \\ Los Alamos National Laboratory/UC/DOE \\ Los Alamos, New Mexico USA 87545 \\ (505)667-9653) LA-UR-99-5816
}

\section{ABSTRACT}

A reliable easy to use, transportable pressure measurement device (Fig.1) for assessing the gas fill in spherical ICF targets is needed for LANL experiments at OMEGA.

This paper describes the burst system design and the method used to calibrate and operate the system. It also presents the first test results.

\section{INTRODUCTION}

The object of this exercise is to measure the internal pressure of small gas filled targets by breaking the target into a vacuum and measuring the resultant pressure rise. An accuracy of order $5 \%$ is adequate in most cases, to indicate that the other targets in the same manufacturing and fill run retain the gas pressure required by the implosion experiment. This measurement was made necessary by loss of data in several experiments that brought into question the actual fill pressure of the targets. A request to design, build, and operate a direct measurement system was made.

\section{SYSTEM}

Autoclave Engineers (AE) valves and other plumbing components were chosen for their simple design, small internal volume, reliability, and ease of modification.

Total system volume needs to be as low as possible in order to ensure maximum sensitivity, since one is measuring the incremental increase in pressure in a volume inherently much larger than the volume of the 500 micron diameter target upon breakage of that target. An MKS Baratron model $690 \mathrm{~A}$ was used to measure pressure. This gauge's usable range is $2^{*} 10^{-5}$ to 1000 Torr. The gauge dead

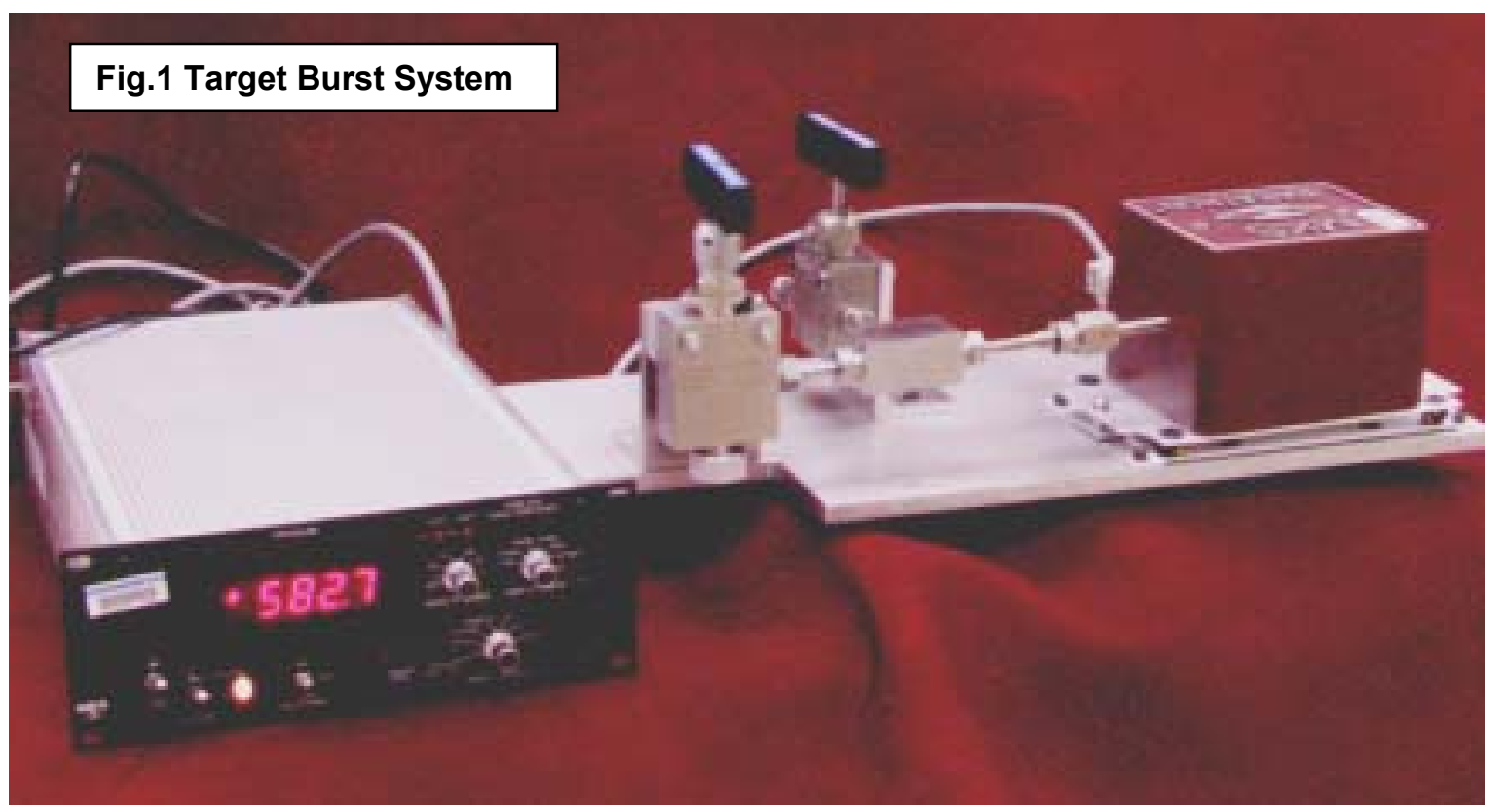


volume of $2.5 \mathrm{cc}$ is the limiting factor in minimizing the total internal volume. A section of the connecting tubing was stuffed with a thick walled modified $A E$ nipple to reduce the volume $0.5 \mathrm{cc}$. A measurement device with a much lower dead volume would be desirable, but the available Baratron gauge provided adequate system sensitivity for these tests. The digital read out is an MKS 270D. An Alcatel ASM110 Turbo CL leak detector was used to supply vacuum and to check for leaks in the system.

The device (Fig.2) used to break a target is a modified AE valve. The holder (Fig. 3) incorporates a bonded-in-place o-ring seal. The cone is the shape of the $A E$ needle part of the valve. The plunger section of the $A E$ valve is a micrometer adjustable needle valve. The lower port was modified to accept a cone shaped holder.
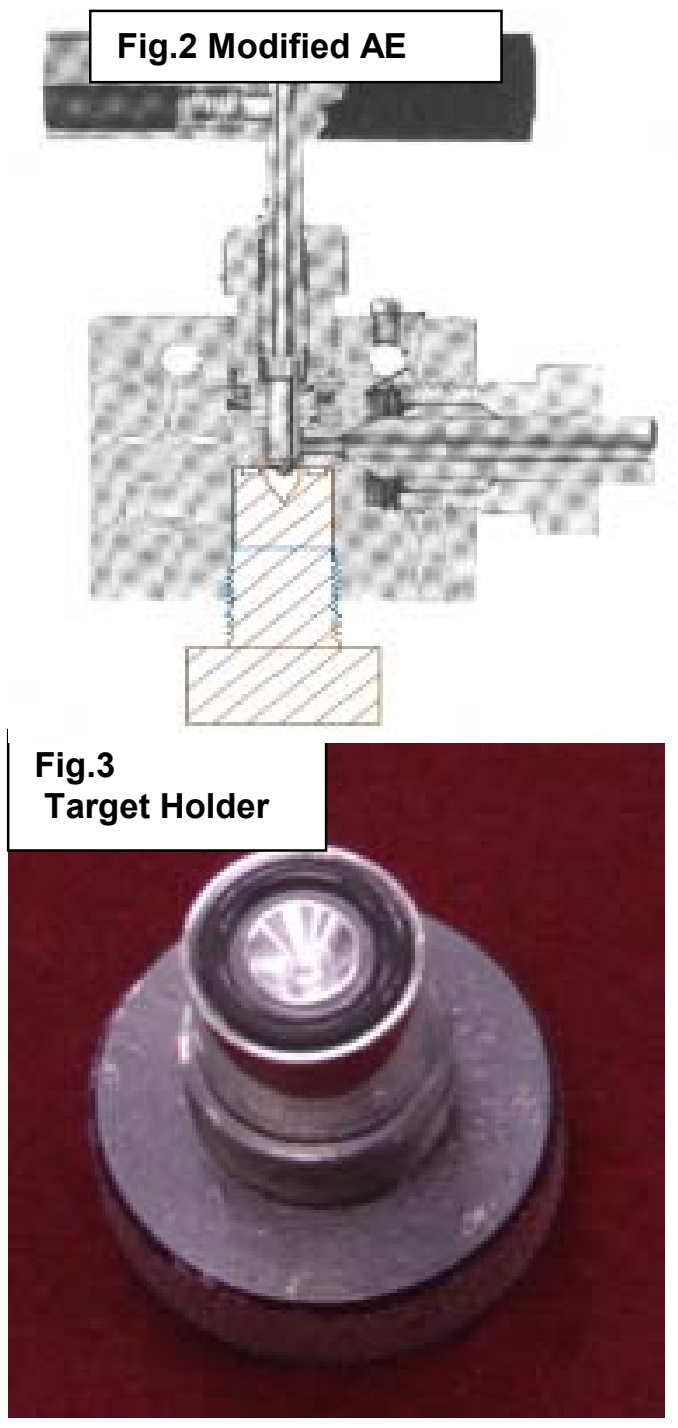

III. Volume Calibration
Calibration was accomplished by moving the stem of the modified $A E$ valve a precise distance, $0.254 \mathrm{~cm}$, thereby reducing the internal volume. $0.031 \mathrm{cc}$. This change in volume produces a rise in pressure (Fig. 4). For initial pressures of about 100 Torr, this rise is on the order of 1 Torr, which is easily resolved by the instruments in the system. Using the data generated by these measurements, a volume for the system was calculated. The standard

\begin{tabular}{|c|c|c|}
\hline Fig. 4 Volume Calibration & & \\
\hline Pressure open Torr & $\begin{array}{l}\text { Pressure } \\
\text { closed } \\
\text { Torr }\end{array}$ & $\begin{array}{l}\text { Volume } \\
\text { of } \\
\text { system } \\
\text { open cc }\end{array}$ \\
\hline 94.74 & 95.71 & 3.059 \\
\hline 94.85 & 95.80 & 3.126 \\
\hline 94.87 & 95.83 & 3.095 \\
\hline 94.92 & 95.87 & 3.128 \\
\hline 94.95 & 95.90 & 3.129 \\
\hline 94.96 & 95.92 & 3.097 \\
\hline 95.00 & 95.94 & 3.164 \\
\hline 95.01 & 95.96 & 3.131 \\
\hline 95.04 & 95.98 & 3.165 \\
\hline 95.04 & 95.98 & 3.165 \\
\hline & Standard & 0.035 \\
\hline & Dev. & \\
\hline & Average & 3.126 \\
\hline
\end{tabular}

deviation of 10 measurements of the volume thus determined was about $1 \%$ of the average volume of $3.126 \mathrm{cc}$. The precision of this volume determination was considered more than adequate for our purposes.

Pressure rise versus stem movement is linear as shown in Fig.5. This is expected behavior of a well characterized mechanical device.

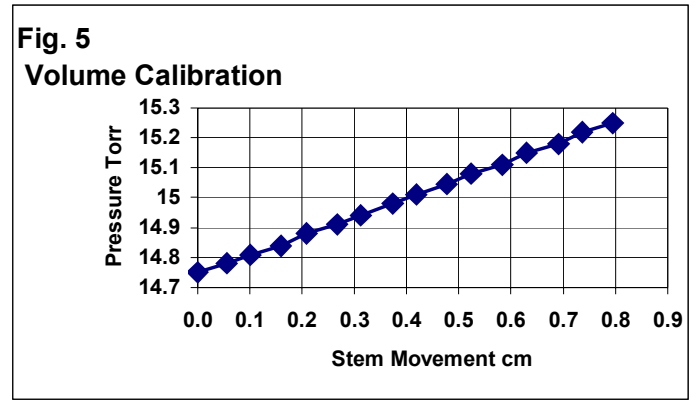

\section{TARGET PRESSURE MEASUREMENTS}

A target is placed into the holder and the holder inserted into the modified $A E$ valve and screwed in to a hard stop. The valve stem is in a retracted position at this stage so that no pressure is applied to the fragile target during insertion. The system is evacuated to less than 0.2 Torr. The stem is moved 
until the needle crushes the target, breaking it and releasing the gas contained in it (at a pressure of 5$100 \mathrm{~atm})$ at which point the system registers a pressure rise. Using Boyle's Law ( $P V=$ constant) the internal pressure of the target can be calculated.

The spherical targets measured (Fig. 6) were from a batch of targets destined for experiments at the Omega laser at Rochester, N.Y.

\begin{tabular}{|c|c|}
\hline $\begin{array}{l}\text { Fig. } 6 \text { Sphere } \\
\text { Tests }\end{array}$ & \\
\hline $\begin{array}{l}\text { Estimated Fill } \\
\text { Pressure atm }\end{array}$ & $\begin{array}{l}\text { Measured Target } \\
\text { Pressure atm }\end{array}$ \\
\hline 4 & $4.5 \pm .25$ \\
\hline 50 & $49.8 \pm .25$ \\
\hline 7 & $7.8 \pm .25$ \\
\hline 10 & $10.7 \pm .25$ \\
\hline
\end{tabular}

Some measurements were made with the system not totally evacuated before bursting. In principal, this is not a problem, since we determine the pressure increase at burst. Practically, however, this causes a complication, since this initial pressure increases as the stem is lowered (volume decreased) to crush the target. For small targets, containing small fill pressures with consequent small pressure jumps upon breakage, this effect, combined with drift in the Baratron gauge, and the ever-present fear of some slight leak, makes the uncertainty in the measurement larger than is inherent in such a system. This uncertainty could be reduced in a future version of the system by recording a time history of the gauge pressure automatically as the stem is inserted, thus tracking all variations in pressure on a rapid (sub-second) time scale. Given such a waveform, gauge instability and slow leak rate drifts, as well as the actual rapid pressure jump upon breakage could be more accurately followed. This would allow better compensation for such effects in the data analysis than was done in these initial tests where the pressure was simply recorded before and after the pressure jump.

For our application, Boyle's law has the form, $\Delta \mathrm{P}^{*} \mathrm{~V}_{\text {sys }}=\mathrm{P}_{\text {cap }}{ }^{*} \mathrm{~V}_{\text {cap }}$, where $\Delta \mathrm{P}$ is the change in gauge pressure when the target breaks, $V_{\text {sys }}$ is the volume of our system $(3.12 \mathrm{cc}), \mathrm{P}_{\text {cap }}$ is the pressure within the target, and $V_{\text {cap }}$ is the interior volume of the target. For the $440 \mu \mathrm{m}$ i.d. targets, we simply have $\mathrm{P}_{\text {cap }}(\mathrm{atm})=92 \Delta \mathrm{P}$ (Torr). Consequently, the approximately 2-3 mTorr fluctuations in our gauge result in an uncertainty in target pressure of about $0.25 \mathrm{~atm}$, independent of fill.

For these targets, with a nominal O.D. of $550 \mu \mathrm{m}$ and an I.D of $440 \mu \mathrm{m}$, the volume of target material
(GDP) is about $5^{\star} 10^{-5} \mathrm{cc}$, which is thus entirely negligible. Only if the ratio of target material volume to system volume increased $\sim 3$ orders of magnitude would we have to take this volume into account.

We have also used this apparatus on test gasfilled parts that are precursors to NIF beryllium targets ${ }^{1}$. A 2-part copper cylinder, with an internal spherical cavity of $1.90 \mathrm{~mm}$ diameter, was filled and brazed while under 50 atmospheres of argon. A modified target holder (similar to that of Fig. 3, but with a cylindrical internal shape) was used to confine the copper part during burst testing. With the system re-calibrated for this new holder, the cylinder was burst tested and determined to have held a pressure of 49.12 atmospheres. This value was within $1 \%$ of the pressure determined by weighing the cylinder before and after bursting.

\section{CONCLUSION}

This is a reliable method for the measurement of target pressure. We can use this device to measure pressures in a target up to NIF pressures. This method is not user sensitive as the user follows a script, takes data from a digital readout, and records the data into a spreadsheet. The results are calculated in the spreadsheet and reported immediately. Compared to bursting a target under glycerin $^{2}$ this technique definitely requires less practical skill for the occasional user.

\footnotetext{
${ }^{1}$ R. W. Margevicius, L. J. Salzer, G. Rivera, A. Nobile, M. A. Salazar, T. J. Asaki, and L. R. Foreman, Los Alamos National Laboratory, Los Alamos New Mexico, USA

"Fabrication and Filling of NIF-sized Beryllium Alloy Targets"

Target Fabrication Meeting 99
}

${ }^{2}$ W. B. Rensel, T. M. Henderson and D. E. Solomon KMS Fusion, Inc., Ann Arbor, Michigan 48104 "Novel method for measuring total pressure of fuel gas in hollow, glass Micro targets pellets"

.Rev. Sci. Instrum., No. 6, June 1975 